\title{
Management of mechanical engineering design processes based on product cost estimates
}

\author{
Evgueniy Kolbachev ${ }^{1, *}$ \\ ${ }^{1}$ South-Russian State Polytechnical University, Production and Innovation Management dept., Novocherkassk, Russia
}

\begin{abstract}
It is herein conjectured that the cost of a machine can be estimated early in the engineering process. Such estimation is based on an integral index of its informational (parametric) complexity. The index also factors in the properties of materials in use as well as the structural components of machine parts. The author has designed an original approach to the management of design processes, which approach is based on the structural index entropy. The entropy level decreases as the structure is optimized. Using the economic parameters should also help decrease such entropy. The author herein presents the instruments for estimating the parametric complexity of a structure. This index may then be used to calculate the projected costs of the structure.
\end{abstract}

\section{Introduction}

Current conditions of the world economy make increasing of the businesses' competitiveness in the market an actual task for the mechanical engineering design and manufacturing enterprises. Main causes of the situation are the re-industrialization processes and development of the knowledge economy.

Reasons for the development of re-industrialization processes that take place in the later years all over the world may differ due to a concrete country [1]. For example, authors of the well-known report [2] contend that the reasons for re-industrialization in the USA are the following: unit labor costs are among the lowest in the industrialized world; the cost of capital is very low given the Fed's ultra-accommodative monetary policy. The similar processes take place in the European countries [3]. Re-industrialization gives the mechanical engineering and manufacturing enterprises a possibility to "come back" to these countries, and also creates incentives for development of the new enterprises. Parameters of these enterprises' product (first of all, the machines and mechanisms) should be very close to the economically optimum.

In the newly industrialized countries (mainly, in the Southeast Asia) modern high-tech industry was developed in the end of 20th century because of the manufacturing move to the region from the industrially developed countries, and the appropriate economic policy of the government. Now the actual task for them is development of the "original" mechanical engineering industry that is independent of the foreign companies' policy of manufacturing development, and switch from copying of the western constructions to the carrying out of the original engineering projects. It's noticeable that the numerous well-known publications in the field of economic management for the engineering design in the last years were presented by authors from the newly industrialized countries $[4,5,6]$.

A reason for the re-industrialization of the last years in Russia is understanding by the society and the national government how important the increasing of country's human capital. A catastrophic decreasing of the human capital level in Russia took place in the beginning of the post-Soviet period due to the destructive government policy and resulted in the elimination of many science intensive sectors of Russian economy [7]. The policy of the EU countries and of the USA that restricts the scientific and technical cooperation between Russian and foreign corporations after the coup d'etat in the Ukraine in 2014 finally favours the development of Russian mechanical engineering [8].

So we can say that problem solving in the field of managing the mechanical engineering design processes and working out of the new machines is actual all over the world. Solving of these problems increases the competitiveness level of the engineering products and of the mechanical engineering corporations.

One of the steps in this direction may be a researching of the existing and working out of the new methods and instruments for the valuation of constructs' cost at an early stage of the engineering. Using of the organizational and economic methods for the managing of the engineering design is also appropriate to succeed.

\section{Managing the engineering design and entropy of the construct}

Valuation of the construct's cost at an early stage of the engineering is an important task because it increases the level of "informational completeness". The higher the 
level is the closer construct's parameters will be to the optimum.

The level of construct's approximating to the optimum condition may be presented as a level of the construct's entropy. Decreasing of the entropy level means that the construct's conditions become closer to the optimum. We can use this dependence because during the development and analyzing of the different versions of the construct the number of the possible (potential) versions to choose the optimum construct of them decreases. Each of the versions is a step to the optimum.

We can evaluate the construct's entropy level using the Shannon's formula [9]:

$$
H=c\left(p_{1} \ln \frac{1}{p_{1}}+p_{2} \ln \frac{1}{p_{2}}+\ldots+p_{n} \ln \frac{1}{p_{n}}\right),
$$

The used measurands are: $H$ - entropy of the construct; $p_{1}, \ldots p_{n}$ - state probabilities of the construct's elements; $c$ - the constant.

We have to take into account that during the analysis of the construct's elements and the combinations of them we examine only the material components of the system and structure of these components. The non-material components (such as databases, thesaurus of the certain employees and other informational resources, used in the "classical" Shannon's formula) shouldn't be examined.

As the most applicable in the analyzed situation we are going to use the conditional entropy index, derived by A. Renyi [10]. The essence of the presented approach is the following.

Let $B$ is a randomly chosen version of the construct, and the probability of the choice is positive; $\xi$ is a random variable that possesses the values $x_{1}, x_{2}, \ldots, x_{n}$. We denote by $A_{k}$ the derivative of $B$, a version of construct which's $\xi=x_{k}(k=1,2, \ldots, N)$. Then basing on the definition, we determine the conditional entropy of $\xi$ under the condition $B$ as an entropy of the random variable $\xi$, calculated on the base of the conditional probabilities' distribution. It's taken that that the construct version $B$ is created. So we derive the equation.

$$
H_{B}(\xi)=\sum P\left(A_{k} \mid B\right) \log _{2} \frac{1}{P\left(A_{k} \mid B\right)},
$$

$P\left(A_{k} \mid B\right)$ is a conditional probability of the version $A_{k}$ under the condition $B$ ( $B$ is taken as the initial version), so the equality is the following.

$$
P\left(A_{k} \mid B\right)=\frac{P\left(A_{k} B\right)}{P(B)}
$$

Let $\eta$ is another version of the construct, which's characteristics possess the values $y_{1}, y_{2}, \ldots, y_{m}$, and $B$ is a version $\eta=y_{j}(j=1,2, \ldots, M)$. Then the conditional entropy of $\xi$ when the version $\eta$ is created is $H_{\eta}(\xi)$, that is definitely similar to the expectation value of $H_{B j}(\xi)$.

$$
H_{\eta}(\xi)=\sum P\left(B_{j}\right) H_{B_{j}}(\xi)=\sum \sum P\left(A_{k} B_{j}\right) \log _{2} \frac{P\left(B_{j}\right)}{P\left(A_{k} B_{j}\right)} \text {. }
$$

In the analyzed situation we should take into account the entropy of random variable $\xi$ (the uncertainty of $\xi$ value), and how it decreases during the examining of the randomly chosen version of the construct $\eta$. A value of the entropy quantity we designate as $I(\xi, \eta)$. It is a quantity of information about randomly chosen value $\xi$ that we get during the examining of randomly chosen version of construct $\eta$.

$$
\begin{aligned}
I(\xi, \eta)= & H(\xi)-H_{\eta}(\xi)=\sum P\left(A_{k}\right) \log _{2} \frac{1}{P\left(A_{k}\right)}- \\
& -\sum \sum P\left(A_{k} B_{j}\right) \log _{2} \frac{P\left(B_{j}\right)}{P\left(A_{k} B_{j}\right)} .
\end{aligned}
$$

Then we use the identity.

$$
\sum_{j} P\left(A_{k} B_{j}\right)=P\left(A_{k}\right)
$$

We can use it because the versions $A_{k} B_{1}, A_{k} B_{2}, \ldots$, $A_{k} B_{M}$ are mutually exclusive, and if the construct version $A_{k}$, is created, creation of any other version of $A_{k} B_{j}$ is possible too

Basing on the above we can label any problem that exists during the engineering design processes as a result of shortage of the information about construct's elements. So, using the information about cost characteristics of the construct's version is a possible way to solve the problem.

\section{Methods of valuation the constructs' cost at an early stage of the engineering}

Production cost characteristics of the constructs, or their parts include the materials output ratio; labour output ratio (this index also includes the time of using machinery for the processing of the details); total investment costs for the building-up and launching of the production.

The machine's cost is an integral characteristic that includes all types of the production costs that exist during the engineering and production. Exact calculation of the machine's cost may be done only basing on the full set of engineering and design documentation. But at an early stage of the engineering this set of documentation does not exist. To prognosticate the cost value on this stage the numerous rough-and-ready methods may be used. A great variety of methods is a result working out each of them for the certain organizational and technical conditions of engineering. Choosing an appropriate method of cost estimating at an early stage of the engineering is a basis for the right economic justification of the project. Objective cost estimation at an early stage of the engineering stimulates the fastest appearance of the new machine in the market, decreases the costs level and increases the quality. As a result, the cost estimating gives a possibility to make a machine with higher competitiveness indexes in the open market.

The earliest researches in this field were taken out in Germany in the 1950th — 1980th by K. Ehrlenspiel, 
A. Kievert, U. Lindemann (1980) [11]; G. Pahl, K. Beelich (1987) [12] et. al. The results of this work were summarized by H. Warnecke, H. Bullinger, R. Hichert, A. Voegle in the well-known work [13].

Some of the researches in the field of economic valuation of the engineering production and working out the economic methods for the engineering were carried out in the USSR in 1980th. The attention is to be paid to the works by A. Kovalev [14], N. Moisseeva [15], et. al. Unfortunately, Russian research projects in this field were broken off, and numerous enterprises that used the results of the researches were eradicated in the 1990th, in the period when management of national economy was ruled by Eltsyn's and Gaidar's cabinet, based on the guidelines, presented by advisers from the USA [7]. The said researches were resumed in Russia in the 2000th and became especially successful after the beginning of Russian industry's rapid development and increasing its competitiveness level in 2014 and after (V. Kovalskiy (2012); D. Zavadskiy (2015); E. Kolbachev and O. Sukharev (2016) [16, 17, 18]). The reason for this process was overcoming the unsuccessful economic blockade of Russia by the USA an EU.

At the same time there was presented a well-known method of cost estimation at an early stage of the engineering by C. Ou-Yang and T. Lin [19]. It was based on the information, used in the CAD systems. Y. Jung [5] worked out an original classification of the machine components to estimate the cost of their processing. The original model of cost estimation at an early stage of the working out the processes for the milling works was presented by E. Nasr and S. Kamrani [4]. Using these models as a basis gives a possibility to work out the universal models of cost estimation. Another interesting research is a known work by E. Maraghy, W. H. Urbanic and R. Jill [20]. These authors worked out an algorithm of estimating the complexity factor for the processes of the machinery details production. The algorithm doesn't deal with the details' costs, but may be improved and used for the cost estimation.

A special attention should be paid to the recently published work by H. Budiono, G. Kiswanto and T. Soemardi (2014). Authors present an original method of cost estimating at an early stage of the engineering design processes. Method is based on the using of correlation between the cost indexes and complexity level of the processing, and takes into account the features of the specific details. The method gives design engineers a possibility to create and analyze the alternative versions of the construct as fast as possible.

In the majority of cases the well-known methods of valuation the constructs' cost at an early stage of the engineering are based on the statistical data about the cost of processing the certain part (or surface) of the detail. This group of methods is worked out by G. Pahl and K. Beelich (1987) [12]; A. Kovalev (1986) [14]; P. Duverli and J. M. Castelain (1999) [21] etc.

Some of the methods were worked out for the details, which can be proceeded by the limited number of ways (for example, milling work), such as methods by H. Budiono, G. Kiswanto, T. Soemardi (2014) [6]. Others (by S. Duglas, T. Gilbert, S. Gilbert (2014)) [22] are worked out for the processing, based on the additive work, or on the special conditions of making the certain product (V. Mallikarjuna (2014)) [22].

In the last years the numerous works in the said field were taken out only to solve the specific task of valuating the costs in CAD and CAM systems (works by P. Karam (2007) [24]; C. Shaw, Y. Eugene (2000) [25]; V. Mallikarjuna (2014) [22] etc.

Besides that, most of the known methods of valuation take into account the processing costs, but not the material costs.

The said features of the known cost estimating methods are extensively reviewed in the Cost Estimating Guide (2011) [26].

The said makes the constructs' cost estimating at an early stage of the engineering design processes much more complicated, and the managing of new machines engineering becomes less efficient.

Our goal is to create a methodology of the constructs' cost estimating at an early stage of the engineering design without these limitations.

\section{Construct's informational complexity as a basis for the cost estimating}

A basic feature that differs our methodology from the well-known alternatives is that cost estimating of the detail part is based not on the construction parameters (such as size, dimensional accuracy, surface smoothness etc.), but on the integral index of its informational complexity.

Original algorithm of the cost detail parts' cost estimating, based on the said methodology is presented in Fig. 1. Formation of the database "The unit costs" looks like the most tedious part of its realization. The database should contain the information about the detail part's cost characteristics per unit of its informational complexity. The database formation requires realizing of such subgoals as classification of the objects for the empirical study and adaptation of the results for the requirements of the specific enterprise.

It's obvious that realizing of the said goals is impossible without choosing of an index, which index is to be used to indicate a level of the informational complexity. Basing on the results of research we established that the most suitable index for the serial production of the machinery detail parts is the index of parameter complexity per unit of detail's mass. Algorithm of the database "The unit costs" formation is presented in Fig. 2. The index of parameter complexity is being determined here as a code combination of the details' dimensional and other engineering parameters per unit of detail's mass. The index is to be added to the informational valuation of the used material. The valuation is based on the number of material's 


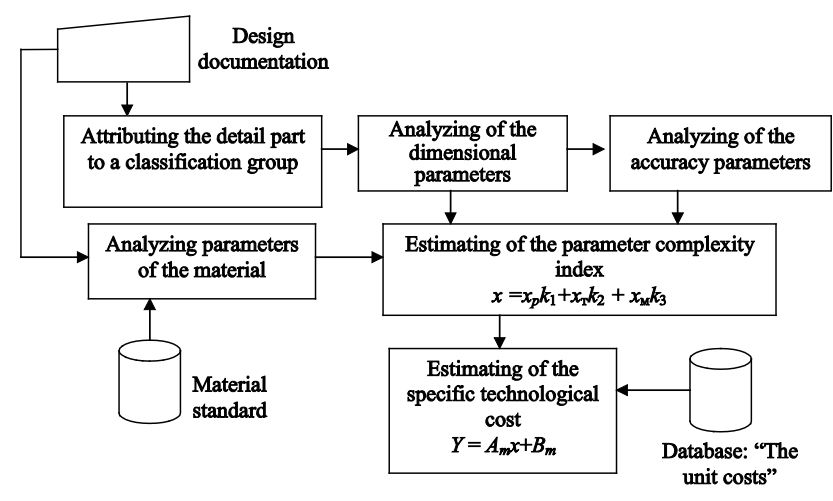

Fig. 1. Schematic diagram of the details' cost estimating based on the integral index of the informational (parameter) complexity.

parameters (these parameters are to be specified in the material standard).

As an example of calculating the indexes of details' unit costs we presented Table 1. It is the empirical dependence of some detail parts categories' costs from their informational complexity. The dependence is ascertained basing on research data we got as a result of the exploring the mechanical engineering enterprises in the South of Russia.

In the presented in Table 1 dependence formula $Y$ is detail parts' specific technological cost (rubles per kg), $x$ is a parametric complexity index. Complexity index was determined for the each detail part according to the algorithm in Fig. 1.

Values of Fisher's criterion and t-statistics ratio mean that the obtained models and regression coefficients are statistically essential. Presented results give us a possibility to suggest a hypothesis that the dependence of the models' cost characteristics (for the widely used in the engineering design detail parts) from their parametric complexity index is a kind of linear dependence.

To our minds, a presented hypothesis may be used as a methodological basis for the future working out of the economic projecting subsystem for the existing engineering design CAD systems.

In the South-Russian State Polytechnical University's department of Production and Innovation Management are being worked out some economic instruments, based on the presented research results. The instruments should be used for the managing of engineering design

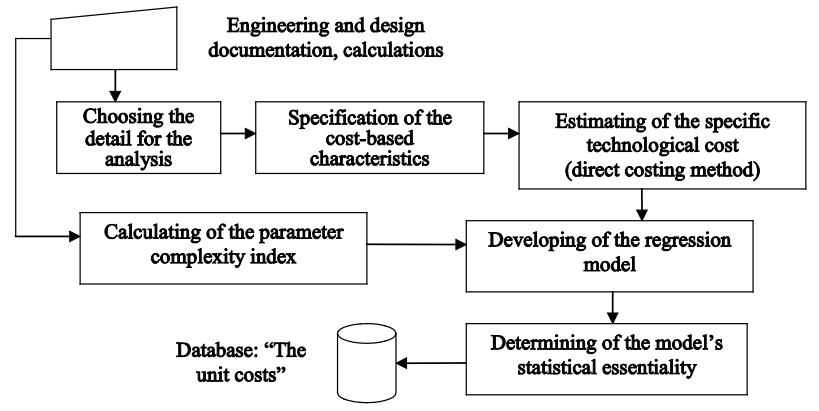

Fig. 2. "The unit costs" database: schematic diagram of the formation.

processes inside the mechanical engineering cluster and its innovation infrastructure [27] (M. Perederiy (2015)).

\section{Conclusion}

The basic goal of the presented research was determining of the economic (institutional) essence of engineering design. As a basis we used the valuation of construct's cost characteristics. Also on this basis were worked out some instruments of managing the engineering design processes. Using of the instruments should increase the engineering and production enterprises' competitiveness level.

As a result of the research there was established a fact that the ways of increasing engineering and production enterprises' competitiveness level differs greatly in the different countries of the world. The countries, which lead in the technical and economical fields, should choose the ways, based on reindustrialization processes. The newly industrialized countries (first of all, countries of the Southeast Asia) should develop the independent mechanical engineering industries, without western companies' participation. Russia's way is maintenance of the country's political and economic sovereignty and restoration of industry (first of all, it high-tech branches) after the collapse of the 1990th - early 2000th years.

As a result of the analysis of the numerous wellknown methods of valuation the constructs' cost at an early stage of the engineering was worked out an original approach to estimating of the construct's prospective cost. The approach is based on using of the

Table 1. Detail parts cost's empirical dependence from their parametric complexity level.

\begin{tabular}{|c|c|c|c|c|c|c|c|}
\hline $\begin{array}{c}\text { Group of the } \\
\text { detail parts }\end{array}$ & $\begin{array}{c}\text { Number } \\
\text { of the } \\
\text { obser- } \\
\text { vations } \\
\text { (pairs) }\end{array}$ & Model & $\begin{array}{c}\text { Determi- } \\
\text { nation } \\
\text { coeffici- } \\
\text { ent }\end{array}$ & $\begin{array}{c}\text { Calculated } \\
\text { value of the } \\
\text { Fisher's } \\
\text { criterion }\end{array}$ & $\begin{array}{c}\text { Critical } \\
\text { value } \\
\text { of the } \\
\text { Fisher's } \\
\text { criterion, } \\
\text { confidence } \\
\text { level } \mathbf{0 . 0 5}\end{array}$ & $\begin{array}{c}\text { t-statistics } \\
\text { ratio of the } \\
\text { regression } \\
\text { coefficient } \\
\text { valuation }\end{array}$ & $\begin{array}{c}\text { Critical } \\
\text { value } \\
\text { of the } \\
\text { t-criterion, } \\
\text { confidence } \\
\text { level } \mathbf{0 . 0 5}\end{array}$ \\
\hline Shafts & 253 & $Y=0.3965 x+19.63$ & 0.946 & 314.05 & 4.45 & 17.72 & 1.7459 \\
\hline Bushes & 144 & $Y=0.275 x+30.88$ & 0.935 & 131.25 & 5.32 & 11.46 & 1.8595 \\
\hline Gears & 185 & $Y=0.904 x-56.51$ & 0.953 & 326.61 & 4.54 & 18.07 & 1.7613 \\
\hline Box housings & 92 & $Y=0.5529 x+27.749$ & 0.85 & 153.88 & 4.22 & 12.40 & 1.7109 \\
\hline Bed-plates & 114 & $Y=0.438 x+50.388$ & 0.825 & 76.63 & 4.54 & 8.75 & 1.753 \\
\hline
\end{tabular}


integral index of the construct's informational (parametric) complexity. The approach also takes into account the features of used materials and the aggregate of the construct's detail parts.

As an addition for the cost characteristics estimating methods we worked out the approach to managing of engineering design processes, based on the construct's entropy level. The level of the entropy decreases during the construct's characteristics become closer to the optimum.

A presented approach gives a chance to make managing of engineering design processes more efficient, and the worked out machinery - more competitive in the nowadays open market.

The results of the research confirm a theory that using a methodology of the construct's economic valuation at an early stage of engineering is appropriate.

\section{References}

1. D. North, B. Goutard, The Reindustrialization of the U.S. - A 2014 Update (Euler Hermes, Paris, 2014)

2. The Reindustrialization of the United States. Spec. Rep. no. 1187 (Euler Hermes, Paris, 2013)

3. Reindustrialization of Europe - Minerals Industry Contribution. Press release (European Association of Mining Industries, Metal Ores \& Industrial Minerals, Brussels, 2014)

4. E.S.A. Nasr, A.K. Kamrani, Computers \& Industr. Engineering, 51, 389-415 (2006)

5. J.-Y. Jung, J. Intell. Manufact., 4, 227-238 (2002)

6. D.S. Budiono, G. Kiswanto, T. Soemardi, Intern. J. of Technol., 2, 183-192 (2014)

7. M. Delyagin, Russia for the Russians (Eksmo, Moscow, 2009)

8. I.V. Mukhanova, Econ. J., 2(38), 34-41 (2015)

9. C.E. Shannon, Bell System Tech. J., 27, 423 (1948)

10. A. Renyi, Dialogues on Mathematics (Holden-Day, New-York, 1967)

11. K. Ehrlenspiel, A. Kievert, U. Lindemann, VDI J., 17, 11 (1980)

12. G. Pahl, K. Beelich, Construction, 7, 10 (1987)
13. H.J. Warnecke, H.J. Bullinger, R. Hichert, A. Voegele, Cost Estimation and Accaunting for the Engineers (Hanser-Verlag, Munich, 1996)

14. A.P. Kovalev, Making the Worked-out Machinery Efficient (Mechanical engineering, Moscow, 1986)

15. N.K. Moisseeva, Functional and Costs Analysis for the Machine-building (Mechanical engineering, Moscow, 1987)

16. D.Ju. Zavadskiy, Fundamental Res., 7, 387-393 (2015)

17. V.F. Kovalsky, S.V. Kovalsky, M.Ju. Chalova, Railway Track and Track Facilities, 11, 21-24 (2012)

18. E.B. Kolbachev, O.S. Sukharev, Economic Methods for the Engineering Design and Machinery Manufacturing (Akademcenter, Rostov-on-Don, 2016)

19. C. Ou-Yang, T.S. Lin, Int. J. of Advanced Manufact. Tech., 13, 618-639 (1997)

20. W.H. el Maraghy, R.J. Urbanic, Modelling of Manufacturing Systems Complexity (Windsor, Ontario, CA, Intelligent Manufacturing Systems (IMS) Centre, 2003)

21. P. Duverli, J.M. Castelain, Int. J. of Advanced Manufact. Tech., 15, 895-906 (1999)

22. S. Douglas, D.S. Thomas, S. Gilbert, Costs and Cost Effectiveness of Additive Manufacturing (U.S. Department of Commerce, New-York, 2014)

23. V. Mallikarjuna, N. Jashuva, G. Nagaraju, B. Rama Bhupal Reddy, J. of Mech. and Civil Engineer. (IOSR-JMCE), 1, 53-67 (2014)

24. K.-A. Karam, Engineer. \& Tech., 1, 103-116 (2007)

25. C.F. Shaw, Y.S. Eugene, Information Modeling of Conceptual Process Planning Integrated with Conceptual Design (The ASME Design Engineer. Tech. Conf., 2000)

26. Cost Estimating Guide (U.S. Department of Energy, Washington, 2011)

27. M.V. Perederiy, Bull. of SRSTU (NPI): Soc. and Econom. Sci., 5, 30-34 (2015) 